\title{
Antimicrobial Resistance Pattern of Enterobacter Species Isolated from Different Clinical Specimens in a Tertiary Care Hospital of Bangladesh
}

\author{
Mashrura Quraishi', Ahmed Abu Saleh¹, Chandan Kumar Roy'1, Fatima Afroz ${ }^{1}$, GM Mohiuddin'1 \\ ${ }^{1}$ Department of Microbiology and Immunology, Bangabandhu Sheikh Mujib Medical University
}

\begin{abstract}
The present study was undertaken to determine the antimicrobial resistance pattern of Enterobacter species to guide the clinician in selecting the best antimicrobial agent for an individual patient. A total of 50 clinical isolates of Enterobacter species were collected from different clinical specimens at the microbiology laboratory of BSMMU between August, 2018 and September, 2019. The two main species of Enterobacter, E.cloacae and E.aerogenes were identified by biochemical tests. Antimicrobial susceptibility testing was performed by Kirby Bauer disc diffusion method and reported according to CLSI guidelines. Majority (56\%) of the isolated Enterobacter were E.cloacae, $40 \%$ were E.aerogenes and $4 \%$ were other species. The Enterobacter isolates showed relatively high resistance rates to the cephalosporins including cefoxitin (82\%), cefixime (62\%), ceftazidime (46\%) and ceftriaxone (46\%). Resistance to the carbapenems and aminoglycosides was relatively low. The high resistance rates of Enterobacter species to multiple antibiotics makes it necessary for antimicrobial susceptibility testing to be conducted prior to antibiotic prescription.
\end{abstract}

Key words: Enterobacter, antimicrobial susceptibility, E.cloacae, E.aerogenes

\section{Introduction}

Enterobacter species are gram negative, facultative anaerobic rods belonging to the family Enterobacteriaceae. Strains belonging to the genus Enterobacter are important opportunistic nosocomial pathogens. Although there are several species of Enterobacter that can cause human disease, E.cloacae and E.aerogenes account for majority of the Enterobacter related infections., ${ }^{1,2}$ Enterobacter have an intrinsic resistance to ampicillin and narrow spectrum cephalosporins. These bacteria possess inducible chromosomally encoded betalactamases and through plasmid mediated resistance, are becoming resistant to manyclasses of antibiotics, including thirdgeneration cephalosporins and carbapenems. ${ }^{3,4,5}$ Resistance of Enterobacter spp. to $3^{\text {rd }}$ generation cephalosporins is most typically caused by overproduction of AmpC beta lactamase that is induced by third generation cephalosporins. These factors pose a challenge in treating Enterobacter infections specially in the hospital setting.

Correspondence:

Dr. Mashrura Quraishi

Department of Microbiology and Immunology

Bangabandhu Sheikh Mujib Medical University, Dhaka.

Phone : 01720643751, E-mail: sharmi.quraishi@gmail.com
This study was aimed to determine the antimicrobial resistance pattern of Enterobacter species isolated from different clinical specimens. Also, common species of Enterobacter causing various infections was identified. This would provide important information regarding the empiric therapy of Enterobacter infections and also reduce treatment failure in hospitalized patients.

\section{Materials and Methods}

Over a period of one year (August 2018 to September 2019), a total of 50 Enterobacter isolates were collected from different samples of urine, blood, wound swab, pus, CSF, tracheal aspirate and peritoneal fluid in the laboratory of Microbiology department of Bangabandhu Sheikh Mujib Medical University, Dhaka.

Antimicrobial susceptibility testing was carried out on the Enterobacter isolates by Kirby Bauer disc diffusion method $^{6}$ using Mueller Hinton agar and commercially available antibiotic discs (Oxoid Ltd, UK). The antibiotics used were mecillinam $(10 \mu \mathrm{g})$, ceftriaxone $(30 \mu \mathrm{g})$, ceftazidime $(30 \mu \mathrm{g})$, cefuroxime $(30 \mu \mathrm{g})$, cefoxitin $(30 \mu \mathrm{g})$, cotrimoxazole $(1.25 / 23.75 \mu \mathrm{g})$, nitrofurantoin $(30 \mu \mathrm{g})$, nalidixic acid $(30 \mu \mathrm{g})$, ciprofloxacin $(5 \mu \mathrm{g})$, gentamicin meropenem $(10 \mu \mathrm{g})$, aztreonam $(30 \mu \mathrm{g})$, cefoxitin $(30 \mu \mathrm{g})$, 
cefixime $(30 \mu \mathrm{g})$, pipercillin-tazobactam $(100 / 10 \mu \mathrm{g})$, tigecycline $(15 \mu \mathrm{g})$, colistin $(10 \mu \mathrm{g})$ and polymyxin B $(200 \mu \mathrm{g})$ was used. The disc content and the zone of inhibition was used as recommended by the Clinical Laboratory Standards Institute (CLSI, 2019). ${ }^{7}$ The zone diameters for colistin, polymyxin B and Tigecycline are not included in CLSI guideline, 2019. In case of tigecycline, zone of inhibition was calculated using European Committee on Antimicrobial Susceptibility testing EUCAST 2016 criteria. ${ }^{8}$ The disc zone diameters were interpreted according to the CLSI 2007 guidelines for colistin (resistant $\leq 10 \mathrm{~mm}$ and susceptible $\geq 11 \mathrm{~mm}$ ) and polymyxin B (resistant $\leq 11 \mathrm{~mm}$ and susceptible $\geq$ $12 \mathrm{~mm}$ ). Susceptibility testing for Tigecycline, Polymyxin $\mathrm{B}$ and colistin was done for isolates that showed resistance to all the antimicrobial agents included in CLSI guideline, 2019. E.coli ATCC 25922 was used for quality control.

Two species of Enterobacter, E.cloacae and E.aerogenes were identified using several biochemical tests including sugar fermentation test for Adonitol, D-sorbitol, L-rhamnose and Esculin and by two decarboxylation reactions- Arginine dihydrolase test and Lysine decarboxylase test. Species other than these two were categorized as others.

\section{Results}

Figure I showed the distribution of isolated Enterobacter into different species. Out of 50 Enterobacter isolates, 28 (54\%) were E.cloacae and $20(42 \%)$ were E. aerogenes. Two isolates (4\%) were categorized as others.

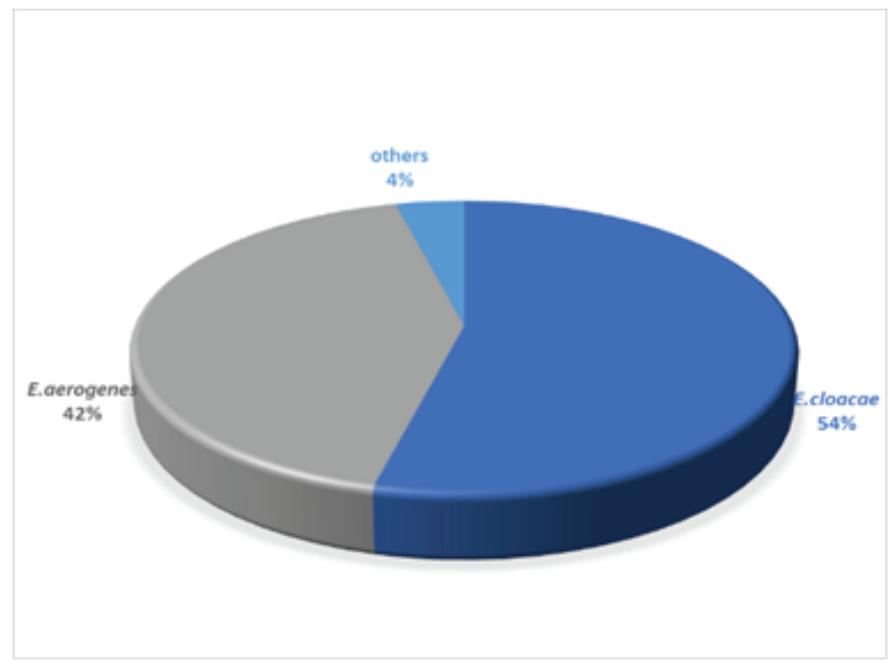

Figure-I: Distribution of Enterobacter isolates into different species
Table I: showed the distribution of Enterobacter isolated from different type of samples. Out of 50 Enterobacter isolates, $34(68 \%)$ were isolated from urine, 7 (14\%) from blood, 4 (8\%) from wound swab and 1(2\%) isolate each from pus, sputum, tracheal aspirate, CSF and peritoneal fluid. Majority of Enterobacter were isolated from urine.

Table-I: Distribution of Enterobacter spp. isolates among different clinical specimens $(\mathbf{n}=\mathbf{5 0})$

\begin{tabular}{|c|c|c|c|c|c|c|c|c|c|}
\hline \multirow[t]{2}{*}{ Species } & \multicolumn{8}{|c|}{ Sample } & \multirow[t]{2}{*}{ Total } \\
\hline & Urine & $\begin{array}{l}\text { Wound } \\
\text { swab }\end{array}$ & Blood & Pus & Sputum & $\begin{array}{l}\text { Tracheal } \\
\text { aspirate }\end{array}$ & CSF & $\begin{array}{l}\text { peritoneal } \\
\text { fluid }\end{array}$ & \\
\hline E.cloacae & 21 & 2 & 5 & 00 & 00 & 00 & 00 & 00 & 28 \\
\hline E.aerogenes & 12 & 1 & 2 & 1 & 1 & 1 & 1 & 1 & 20 \\
\hline Others & 1 & 1 & 00 & 00 & 00 & 00 & 00 & 00 & 02 \\
\hline Total & 34 & 4 & 7 & 1 & 1 & 1 & 1 & 1 & 50 \\
\hline
\end{tabular}

Table-II: Antimicrobial resistance pattern of Enterobacter spp. isolates

\begin{tabular}{|c|c|c|c|}
\hline Antimicrobial agent & $\begin{array}{l}\text { E.cloacae } \\
\mathrm{n}=\mathbf{2 8}(\%)\end{array}$ & $\begin{array}{l}\text { E.aerogenes } \\
\mathbf{n}=20(\%)\end{array}$ & $\begin{array}{l}\text { Total } \\
\mathrm{n}=50(\%)\end{array}$ \\
\hline Ceftazidime & $10(35.7)$ & $12(60)$ & $23(46)$ \\
\hline Cefuroxime & $12(42.9)$ & $14(70)$ & $27(54)$ \\
\hline Cefoxitin & $22(78.6)$ & $17(85)$ & $41(82)$ \\
\hline Cefixime & $15(53.6)$ & $15(75)$ & $31(62)$ \\
\hline Ceftriaxone & $10(35.7)$ & $12(60)$ & $23(46)$ \\
\hline Co-trimoxazole & $8(28.6)$ & $9(45)$ & $18(36)$ \\
\hline Ciprofloxacin & $8(28.6)$ & $9(45)$ & $18(36)$ \\
\hline Nalidixic acid & $11(39.3)$ & $12(60)$ & $25(50)$ \\
\hline $\begin{array}{l}\text { Nitrofurantoin } \\
\text { (urinary isolates } \\
\text { only, } \mathbf{n = 3 4} \text { ) }\end{array}$ & $15(53.6)$ & $07(35)$ & $22(44)$ \\
\hline Gentamicin & 09 (32.1) & $05(25)$ & $15(30)$ \\
\hline Amikacin & $06(21.4)$ & $07(35)$ & $14(28)$ \\
\hline Aztreonam & $09(32.1)$ & $10(50)$ & $20(40)$ \\
\hline Meropenem & $4(14.3)$ & $06(30)$ & $11(22)$ \\
\hline Netilmicin & $6(21.4)$ & $7(35)$ & $14(28)$ \\
\hline $\begin{array}{l}\text { Piperacillin- } \\
\text { tazobactum }\end{array}$ & $7(25)$ & $7(35)$ & $15(30)$ \\
\hline $\begin{array}{l}\text { Ticarcillin- } \\
\text { clavulanate }\end{array}$ & $14(50)$ & $14(70)$ & $30(60)$ \\
\hline $\begin{array}{l}\text { Colistin } \\
(n=10)\end{array}$ & 0 & $2(20)$ & $2(20)$ \\
\hline $\begin{array}{l}\text { Polymyxin B } \\
(\mathrm{n}=10)\end{array}$ & 0 & $2(20)$ & $2(20)$ \\
\hline $\begin{array}{l}\text { Tigecycline } \\
(\mathrm{n}=10)\end{array}$ & 0 & 0 & 0 \\
\hline
\end{tabular}

Intermediate sensitive was considered resistant as MIC of drug was not evaluated 


\section{Discussion}

Enterobacter are normal flora of the human gastrointestinal tract and are also found as commensals in the environment. In recent years, Enterobacter has turned out to be an important agent of nosocomial infections. In this study, out of isolated 50 Enterobacter, E.cloacae (54\%) and E.aerogenes (42\%) were most common. Only $2 \%$ were other species. This finding is similar to studies done by others. A study in Iran reported $77.1 \%$ isolated Enterobacter as E.cloacae and $22.8 \%$ isolates as E.aerogenes. ${ }^{9}$ Another study in China reported $68.2 \%$ blood isolates were E.cloacae and $26.4 \%$ blood isolates were E.aerogenes. ${ }^{10}$

Most of the Enterobacter isolates (68\%) were obtained from urine in this study. This finding is similar to the findings reported in a review article. ${ }^{11}$ Another study in Iran reported $11.5 \%$ Enterobacter were isolated from urine. In this study, 7(14\%) Enterobacter isolates were obtained from blood. The study in Iranreported 18\% Enterobacter isolates were obtained from blood. ${ }^{12}$

In case of antimicrobial resistance, high level of resistance were detected to cefoxitin, cefixime, cefuroxime, ceftazidime and ceftriaxone $(82 \%, 62 \%, 54 \%, 46 \%$ and $46 \%$ respectively) in this study. Similar results were reported by a study in Nepal for ceftazidime, cefixime and ceftriaxone $\left(55.8 \%, 61.8 \%\right.$ and $58.8 \%$ respectively). ${ }^{13}$ This may be due to the production of $\beta$-lactamases, which may be encoded either chromosomally or on plasmids.

In the present study, 36\% of Enterobacter isolates were resistant to co-trimoxazole and ciprofloxacin. A study in Nepal reported similar rate of resistance for these agents (40\% and $44.1 \%$ respectively). ${ }^{14}$ In this study, resistance of Enterobacter to gentamicin, amikacin and piperacillintazobactam was $30 \%, 28 \%$ and $30 \%$ respectively. A study in Nepal reported resistance rate of Enterobacter to amikacin and piperacillin-tazobactum was $35.2 \%$ and $23.5 \%$ respectively. ${ }^{13}$ This may be due to widespread use of broadspectrum antibiotics in our hospitals. Resistance of Enterobacter to meropenem in this study was found $22 \%$. This finding differs with the studies of Nepalwhich reported meropenem resistance $8.8 \%$ and imipenem resistance was $10.5 \% .^{9,13}$ Higher percentage of resistance in this study may be due to higher rate of use of meropenem in our hospitals. In this study, majority of urinary Enterobacter spp. (64.7\%) isolates were resistant to nitrofurantoin. A study in Iran reported $57.1 \%$ urinary Enterobacter isolates were resistant to nitrofurantoin. ${ }^{12}$ Another study in Nepal reported 55.5\% urinary isolates were resistant to nitrofurantoin. ${ }^{13}$ This may be due to injudicial prescription of nitrofurantoin in UTI without doing the sensitivity testing in our country.
Resistance rate of E.aerogenes to most of the antibiotics was higher than E.cloacae isolates, in this study. Resistance rate of E.aerogenes to cefuroxime, ceftazidime and ceftriaxone were $70 \%, 60 \%$ and $60 \%$ respectively whereas for E. cloacae the resistance rates were $42.9 \%, 35.7 \%$ and $35.7 \%$ respectively. Urinary E.cloacae isolates were more resistant (53.6\%) to nitrofurantoin than E.aerogenes (35\%). Resistance rate of E.cloacae and E.aerogenes to gentamicin was $32.1 \%$ and $25 \%$ respectively. E.cloacae showed no resistance to colistin and polymyxin B. These findings differ with the study which reported resistance rates of E.cloacae to antimicrobial agents were higher than E.aerogenes. ${ }^{10}$ The main differences included resistance rates to ciprofloxacin $(63.3 \%$ versus $18.8 \%)$ and aminoglycosides (41.8\% versus $18.8 \%$ against amikacin). There were no significant differences in the resistance rates to third generation cephalosporins. Since the study included only patients with bacteremia and was performed in a single tertiary care hospital, the result may not be applicable to other institutions.

In this study, the most effective antibiotic was tigecycline. None of the isolates were resistant to tigecycline. Only $2(4 \%)$ isolates were resistant to colistin and polymyxin $\mathrm{B}$. This may be attributed to the uncommon use of these drugs in empiric therapy of infections. Thus colistin, polymyxin B and Tigecycline can be good therapeutic options for multidrug resistant Enterobacter infections.

\section{Conclusion}

Enterobacter seems to be emerged with increasing resistance to multiple antibiotics. Extended survey should be launched in larger hospitals of our country to determine the true prevalence of Enterobacter causing nosocomial infections. Regular monitoring of antimicrobial resistance of Enterobacter should be done and Infection control program for prevention of nosocomial infection should be practiced in all the hospitals of our country.

\section{References}

1. Chow JW, Fine MJ, Shlaes DM, et al. Enterobacter bacteremia: clinical features and emergence of antibiotic resistance during therapy. Annals of internal medicine 1991 Oct 15;115(8):585-90.

2. Lee SO, Kim Y, Kim B, Kim MN, Woo JH, Ryu J. Impact of previous use of antibiotics on development of resistance to extended-spectrum cephalosporins in patients with Enterobacter bacteremia. European Journal of Clinical Microbiology and Infectious Diseases 2002 Aug 1;21(8):577-81. 
3. Deshpande LM, Jones RN, Fritsche TR, Sader HS. Occurrence and characterization of carbapenemase-producing Enterobacteriaceae: report from the SENTRY Antimicrobial Surveillance Program (2000-2004). Microbial Drug Resistance 2006 Dec 1;12(4):223-30.

4. Khan AU, Nordmann P. NDM-1-producing Enterobacter cloacae and Klebsiella pneumoniae from diabetic foot ulcers in India. Journal of Medical Microbiology 2012 Mar 1;61(3):454-6.

5. Schultsz C, Geerlings S. Plasmid-mediated resistance in Enterobacteriaceae. Drugs 2012 Jan 1; 72(1):1-6.

6. Bauer AW. Antibiotic susceptibility testing by a standardized single disc method. Am J Clin Pathol 1966;45:149-58.

7. Clinical and Laboratory Standards Institute (CLSI). Performance standards for antimicrobial susceptibility testing. Seventeenth informational supplement. CLSI Document; M100-S17, United States 2007;32-37.

8. EUCAST. The European Committee on Antimicrobial Susceptibility Testing. Breakpoint tables for interpretation of MICs and zone diameters. Version 7.1.2016.

9. Ghanavati R, Emaneini M, Kalantar-Neyestanaki $\mathrm{D}$, et al. Clonal relation and antimicrobial resistance pattern of extended-spectrum $\beta$-lactamase-and AmpC $\beta$-lactamase-producing Enterobacter spp. isolated from different clinical samples in Tehran, Iran. Revista da Sociedade Brasileira de Medicina Tropical 2018 Feb;51(1):88-93.
10. Song EH, Park KH, Jang EY, et al. Comparison of the clinical and microbiologic characteristics of patients with Enterobacter cloacae and Enterobacter aerogenes bacteremia: a prospective observation study. Diagnostic Microbiology and Infectious Disease 2010 Apr 1;66(4):436-40.

11. Davin-Regli A, Lavigne JP, Pagès JM. Enterobacter spp.: update on taxonomy, clinical aspects, and emerging antimicrobial resistance. Clinical microbiology reviews 2019 Sep 18;32(4):e00002-19.

12. Malekzadegan Y, Hadadi M, Ebrahim-Saraie HS, Heidari H, Motamedifar M. Antimicrobial Resistance Pattern and Frequency of Multiple-Drug Resistant Enterobacter Spp. at A Tertiary Care Hospital in Southwest of Iran. Journal of Krishna Institute of Medical Sciences (JKIMSU) 2017 Apr 1;6(2).

13. Adhikari RP, Shrestha S, Rai JR, Amatya R. Antimicrobial Resistance Patterns in Clinical Isolates of Enterobacteriaceae from a Tertiary Care Hospital, Kathmandu, Nepal. Nepalese Medical Journal 2018 Dec 2;1(2):74-8.

14. Dimitrova D, Stoeva T, Markovska R, et al. Molecular Epidemiology of Multidrug Resistant Enterobacter cloacae blood isolates from a University Hospital. Journal of IMAB-Annual Proceeding Scientific Papers 2019 Apr 1;25(2):2457-64. 